\title{
Cutting Parameter Optimization for End Milling Operation Using Advanced Metaheuristic Algorithms
}

\author{
Md Shahriar J Hossain* and T Warren Liao
}

Department of Mechanical and Industrial Engineering, Louisiana State University, USA

Received: May 17, 2017; Accepted: May 30, 2017; Published: June 12, 2017

*Corresponding author: Md ShahriarJ Hossain, Department of Mechanical and Industrial Engineering, Louisiana State University, Baton Rouge, LA 70803, USA, Tel: +1 (225) 937-9990; E-mail: shahriar.jahan.hossain@gmail.com

\begin{abstract}
In die manufacturing industries surface roughness is considered as a vital quality characteristic in order to retain the consumers' satisfaction. On the other hand, manufacturers want to minimize the machining time which eventually reduces their cost. This research deals with an optimization problem to minimize the machining time (T) for end milling operation on hot die steel (H13), subject to specified surface roughness $\left(R_{a}\right)$ limits. Six machining parameters and corresponding $\mathrm{T}$ and $\mathrm{R}_{\mathrm{a}}$ were recorded from 74 independent experiments. After exhaustive search, three machining parameters (tool inclination angle, tool diameter and radial depth of cut) for $\mathrm{R}_{\mathrm{a}}$ and two machining parameters (feed rate and radial depth of cut) for $\mathrm{T}$ are found to be highly influential. In terms of these corresponding parameters, two ANFIS models are developed for the prediction of $R_{a}$ and $T$, respectively. These models are utilized to find the optimum values of machining parameters. Five advanced metaheuristic algorithms, Artificial Bee Colony $(\mathrm{ABC})$, quick artificial bee colony, modified differential evolution, ant colony optimization for real numbers and simulated annealing, with or without local search, are applied for solving this optimization problem. Each of the algorithms is run for 30 times, allowing 100,000 number of function evaluations in each run. Statistical analysis (F-test, t-test) are done to evaluate the performance of the algorithms. Hybrid $\mathrm{ABC}$ with local search is proposed as the best algorithm for solving this problem based on average of minimum machining time obtained. The proposed optimization approach can be used for parameter selection in real time machining with artificially intelligent Computer Numerical Control (CNC) machine tools.
\end{abstract}

Keywords:End milling; Parameter optimization; Surface roughness; Machining time; Metaheuristics;

\section{Introduction}

One of the vital objectives of a die manufacturing industry is to produce high quality dies within a minimum machining time. Surface roughness is treated as an important quality characteristic. As per specifications, the surface of a die should not be too smooth or too rough. Surface roughness as well as machining time for a die depends on several machining parameters of the milling machine including cutter axis inclination angle, tool diameter, spindle speed, radial depth of cut, feed rate and axial depth of cut. Some parameters affect machining time positively and surface roughness negatively or vice versa. These opposing effects eventually lead to the problem for finding the optimum machining parameters that minimize the machining time while satisfying desired surface roughness. It is expected that the next decade machine tools will be intelligent machines with various capabilities, such as self-setting machining parameters to reach to the best surface qualities. In regards of this vision several researchers have been working in recent years in this direction.

Many applications of metaheuristics in Electrical Discharge Machining (EDM) process parameters optimization have been reported in literatures. Mukherjee, et al. [17] applied Genetic Algorithm (GA), Particle Swarm Optimization (PSO), Sheep Flock Algorithm (SFA), ant Colony Optimization (ACO), Artificial Bee Colony (ABC) and biogeography-based optimization (BBO) for single and multi-objective (material removal rate, cutting width, surface roughness and dimensional shift) optimization of wire-EDM processes. Rao and Pawar [19] applied $\mathrm{ABC}$ optimization to find the optimum combination of process parameters for wire-EDM with an objective of achieving maximum machining speed for a desired value of surface finish. Rao and Krishna [20] also conducted wire-EDM machining experiments on Aluminum metal matrix composites reinforced with silicon carbide particulate and developed some empirical models with Response Surface Methodology (RSM) for Surface Roughness (SR), Metal Removal Rate (MRR), and Wire Wear Ratio (WWR) in terms of machining parameters. They did some works on multiobjective optimization for minimizing SR, WWR and maximizing MRR, using GA-II. Pare, et al. [18] explored GA, Simulated Annealing (SA), Teaching-Learning-Based Optimization (TLBO) and Gravitational Search (GS) algorithms to minimize the surface roughness and to determine the optimum machining conditions for the end-milling of composite materials. Teimouri and Baseri [26] also optimized EDM process parameters. They designed ANFIS models to correlate the EDM parameters to material removal rate (MRR) and surface roughness (SR). Continuous ant colony optimization (ACOr) technique was used to select the best process parameters for maximum MRR and specified SR. 
Some applications of metaheuristics are found for turning and milling operations as well. Yildiz [27] presented an optimization approach based on Artificial Bee Colony (ABC) algorithm for optimal selection of cutting parameters in multipass turning operation. Mellal and Williams [16] used a recently developed metaheuristic, called the Cuckoo Optimization Algorithm (COA) for minimization of unit production cost in multi-pass turning process to obtain optimum cutting parameters. Tamizharasan and Bamabas [25] used Particle Swarm Optimization (PSO) and Simulated Annealing (SA) algorithms to obtain the best possible values of cutting tool geometry for the minimization of flank wear in a lathe machine, considering surface roughness as constraint. On the other hand, Kadirgama, et al. [5] optimized cutting parameters for desired surface roughness of milling aluminum alloys with Ant Colony Optimization (ACO).
Silva, et al. [23] did some works for optimizing the production cost subjected to quality constraints in the milling operations on hardened steel. They developed Artificial Neural Networks (ANN) model, and applied Genetic Algorithms (GA) and Mesh Adaptive Direct Search (MADS) algorithms for that purpose. Khanghah, et al. [9] presented their research on optimization of cutting tool geometry for micro-milling applying simulated annealing optimization method on RSM based regression models. Karabulut and Karakoc [8] investigated the machinability of silicon carbide and aluminum alloy-based metal matrix composite during milling operation. Prediction model was developed for the surface roughness through regression analysis and ANN. Some recent research works related to our current research are summarized in Table 1.

\begin{tabular}{|c|c|c|c|c|c|}
\hline Literatures & Applications & Objectives & Variables & Models & Metaheuristics \\
\hline Madic et al. (2014) & $\begin{array}{l}\text { Laser cutting of } \\
\text { stainless steel }\end{array}$ & $\begin{array}{l}\text { Improving quality } \\
\text { characteristics }\end{array}$ & $\begin{array}{l}\text { Power, speed, } \\
\text { pressure }\end{array}$ & ANN & RCGA, SA, IHSA \\
\hline Silva (2014) & $\begin{array}{l}\text { Milling of hardened } \\
\text { steel }\end{array}$ & $\begin{array}{l}\text { Min. Prod. cost } \\
\text { Sub. to quality } \\
\text { constraints }\end{array}$ & Cutting parameters & ANN & GA, MADS \\
\hline $\begin{array}{l}\text { Teimouri and Baseri } \\
\qquad(2014)\end{array}$ & EDM & $\begin{array}{c}\text { Max. } M R R \\
\text { Subject to } S R\end{array}$ & EDM parameters & ANFIS & ACOr \\
\hline $\begin{array}{l}\text { Kadirgama et al. } \\
\qquad(2010)\end{array}$ & $\begin{array}{l}\text { Milling of aluminum } \\
\text { alloys }\end{array}$ & Min. $S R$ & $\begin{array}{l}\text { Speed, Feed rate, } \\
\text { axial and radial } \\
\text { depth }\end{array}$ & RSM & ACO \\
\hline Yusup et al. (2014) & $\begin{array}{l}\text { Abrasive Water-Jet } \\
\text { machining }\end{array}$ & Min. $S R$ & $\begin{array}{l}\text { Machining control } \\
\text { parameters }\end{array}$ & Regression & $\mathrm{ABC}, \mathrm{GA}, \mathrm{SA}$ \\
\hline Yildiz (2013) & Multi-pass turning & Min. Cost & Cutting parameters & Analytical & $\mathrm{ABC}$ \\
\hline $\begin{array}{l}\text { Mukherjee et al. } \\
\qquad(2012)\end{array}$ & Wire-EDM & $\begin{array}{l}\text { Min. } M R R \\
\text { Min. } S R\end{array}$ & Process parameters & ANN & $\begin{array}{c}\text { GA, PSO, SFA, ACO, } \\
\text { ABC, BBO }\end{array}$ \\
\hline $\begin{array}{l}\text { Rao and Pawar } \\
\text { (2009) }\end{array}$ & Wire-EDM & $\begin{array}{l}\text { Max. Machining speed } \\
\text { Subject to. } S R\end{array}$ & Process parameters & RSM & $\mathrm{ABC}$ \\
\hline $\begin{array}{c}\text { Mellal and Williams } \\
\qquad(2015)\end{array}$ & Multi-pass turning & Min. Production cost & Cutting parameters & Analytical & $\mathrm{COA}$ \\
\hline $\begin{array}{c}\text { Khanghah et al. } \\
\text { (2015) }\end{array}$ & Micro-milling & Cutting tool geometry & Speed, feed, depth & RSM & SA \\
\hline $\begin{array}{l}\text { Tamizharasan and } \\
\text { Bamabas (2014) }\end{array}$ & Lathe machine & $\begin{array}{l}\text { Min. Flank wear } \\
\quad \text { Sub. to } S R\end{array}$ & $\begin{array}{l}\text { Cutting tool } \\
\text { geometry }\end{array}$ & Regression & PSO, SA \\
\hline Pare et al. (2015) & $\begin{array}{l}\text { End-milling on metal } \\
\text { matrix composites }\end{array}$ & Min. $S R$ & $\begin{array}{l}\text { Speed, feed, depth, } \\
\text { step-over ratio }\end{array}$ & $\begin{array}{l}\text { Non-linear } \\
\text { regression }\end{array}$ & GA, SA, TLBO, GS \\
\hline $\begin{array}{c}\text { Rao and Krishna } \\
\text { (2014) }\end{array}$ & $\begin{array}{l}\text { Wire-EDM on metal } \\
\text { matrix composites }\end{array}$ & Min. $S R, W W R$ Max. $M R R$ & Process parameters & RSM & GA-II \\
\hline Rong et al. (2016) & Laser brazing welding & Min. Width of weld bead & Feed rate, speed, gap & ELM model & GA \\
\hline $\begin{array}{l}\text { Shukla and Singh } \\
\text { (2017) }\end{array}$ & $\begin{array}{l}\text { Abrasive Water-Jet } \\
\text { machining }\end{array}$ & $\begin{array}{l}\text { Max. kerf width } \\
\text { Min. taper angle }\end{array}$ & $\begin{array}{c}\text { Speed, standoff } \\
\text { distance, flow rate }\end{array}$ & Regression & $\begin{array}{c}\text { PSO, FFA, ABC, SA, } \\
\text { BH, GA }\end{array}$ \\
\hline $\begin{array}{c}\text { Current work by } \\
\text { Hossain and Liao } \\
\text { (2017) }\end{array}$ & $\begin{array}{l}\text { End milling of Hot Die } \\
\text { Steel }\end{array}$ & $\begin{array}{l}\text { Min. Machining Time } \\
\text { Sub. to } S R\end{array}$ & Cutting parameters & ANFIS models & $\begin{array}{c}\mathrm{ABC}, \mathrm{qABC}, \mathrm{SA}, \mathrm{MDE}, \\
\text { ACOr }\end{array}$ \\
\hline
\end{tabular}


Metaheuristics are also applied in some nonconventional machining processes. Yusup, et al. [28] applied ABC, GA and SA algorithms for optimizing the control parameters of Abrasive Waterjet (AWJ) machining that leads to a minimum surface roughness. They have shown that performance of $A B C$ was much superior. Madic, et al. [14] determined the optimum parameter values in the laser cutting of stainless steel with the purpose of improving the quality characteristics. They compared the quality of solutions for optimizing ANN models using the Real Coded Genetic Algorithm (RCGA), Simulated Annealing (SA) and improved harmony search algorithm (IHSA). Rong, et al. [21] optimized the laser brazing welding parameters by a hybrid Extreme Learning Machine (ELM) and Genetic Algorithm (GA) method. Shukla and Singh [22] attempted optimizing water jet machining parameters With Particle Swarm Optimization (PSO), Firefly Algorithm (FFA), Artificial Bee Colony (ABC), Simulated Annealing (SA), Black Hole (BH) and Genetic Algorithm (GA) to maximize kerf top width and to minimize the taper angle.

Many other applications of metaheuristics algorithms are found in machining operations. Liao [11] proposed two versions of ant colony optimization (ACOr and ACO-S) based algorithms for feature selection and applied them to computeraided weld inspections. Liao [12] also investigated feature extraction and feature selection in sensor-based condition monitoring during grinding operations of ceramic materials. He used three different feature selection methods including the ACO based metaheuristics. Zuperl and Cus [29] proposed an approach of using ANFIS to represent the manufacturer's objective function and an Ant Colony Optimization algorithm (ACO) to obtain the optimal objective value. Besides these, Liao [12] presented hybrid differential evolution and harmony search algorithms for optimizing fourteen engineering design problems selected from different engineering fields.

From the literature survey it is evident that many researchers have been conducted with different metaheuristics for optimizing the machining parameters in order to achieve different stated objectives. The advanced algorithms namely, ABC, qABC, ACOr, MDE and SA are widely applied in different field of manufacturing and proved to be efficient and effective. However, the specific applications and comparisons of $\mathrm{ABC}, \mathrm{qABC}, \mathrm{ACOr}$, MDE, SA and their hybrids (with Hill-descent local search) in milling process optimization for hot die steel machining, based on ANFIS models, is very limited. An extensive research in this direction still needs careful attention. Considering this fact, this research presents five different metaheuristics $(A B C, q A B C$, ACOr, SA, MDE) and their hybrids with Hill-descent local search in order to minimize the machining time subject to surface roughness constraints. The objective is to obtain optimum machining parameters for hot die steel machining with a ball end milling cutter. The optimization processes is conducted based on two ANFIS models-one for average surface roughness $\left(R_{a}\right)$ and another for machining time (T).

The paper is organized in a sequential order. The problem is described in problem description section. Methodology section illustrates the method of research. Input Parameter (Variable) Selection Section describes the selection of ANFIS models. The optimization of the problem and the results are discussed in optimization Section. At the end of the article, some concluding remarks are noted in conclusion Section.

\section{Problem Description}

Commercial die manufacturing is directed by customers' satisfaction and profit margins. In order to retain customers' satisfactions, it is essential to make the dies within specifications and to maintain the quality. One of the vital quality characteristics of commercial dies is the surface roughness. A common measure of surface roughness $\left(R_{a}\right)$ is the arithmetic average deviations of the roughness profile from the center line. Maintaining the surface roughness within specification limits sometimes becomes difficult for many die materials, because of the involvement of multiple machining parameters. Whereas, the manufacturers' objective is to minimize the machining time (T). Machine time is defined as the time required removing a certain volume of material. The situation becomes even more complex when machining time and surface roughness depend on some common machining parameters, and the relationship is not linear. As a result minimization of machining time, subject to surface roughness constraints becomes a potential optimization problem.

This research involves the experiments [see Figure 1] conducted by Hossain and Ahmad [4] on a die material Hot die steel (H13) for ball end milling operation. There were six machining parameters concerned with that experiments-cutter axis inclination angle ( $\varphi$ degree), tool diameter $(\mathrm{d} \mathrm{mm})$, spindle speed ( $\mathrm{S} \mathrm{rpm})$, radial depth of cut $\left(\mathrm{f}_{\mathrm{x}} \mathrm{mm}\right)$, feed rate $\left(\mathrm{f}_{\mathrm{y}} \mathrm{mm} / \mathrm{min}\right)$, and axial depth of cut $(\mathrm{t} \mathrm{mm})$. The inclination angle, $\varphi$ represents the angle of the cutter axis with respect to normal direction to the machining surface. On the other hand, Tool diameter results the maximum width of the machined surface in a single pass of the cutter. Spindle speed, $\mathrm{S}$ is defined as the average number of rotations of the spindle per minute. Radial depth of cut, $\mathrm{f}_{\mathrm{x}}$ is the amount of indentation of the tool into the machining surface, while feed rate, $\mathrm{f}_{\mathrm{y}}$ is the amount of linear movement of the cutting tool along a parallel direction to the machining surface. Two dependent variable were measured-surface roughness $R_{a}$ $(\mu \mathrm{m})$ and machining time $\mathrm{T}(\mathrm{min})$. Each specimen surface area was $1 \mathrm{~cm} \times 1 \mathrm{~cm}$. Total 74 experiments were conducted (results are listed in Appendix). Based on these data two, ANFIS models are developed in order to predict $\mathrm{T}$ and $\mathrm{R}_{\mathrm{a}}$, where machining parameters are taken as inputs.

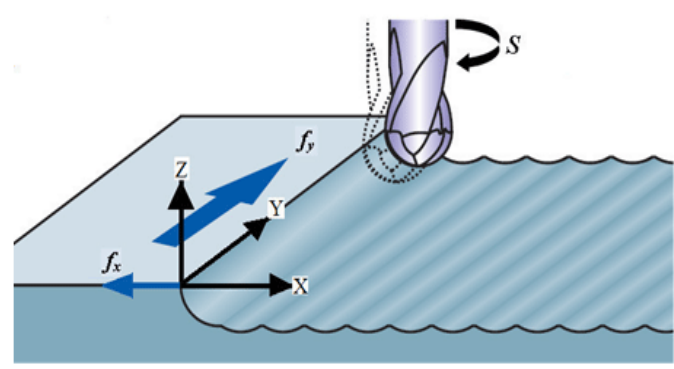

Figure 1:End milling operation 
Now, customer doesn't want the surface of the die too smooth or rough. As per the specifications expected by the customer the surface roughness should be higher than or equal to $0.4 \mu \mathrm{m}$ and should not be higher than $0.6 \mu \mathrm{m}$. Thus the surface roughness constraints become: $0.4 \leq \mathrm{R}_{\mathrm{a}} \leq 0.6(\mu \mathrm{m})$. On the other hand, the manufacturer's objective is to minimize the machining time. The milling machine used in the experiments could deal with only some specific discrete values of tool diameter $(\mathrm{d} \mathrm{mm})$ and the spindle speed (S rpm). Other variables are continuous within some boundaries.

So the optimization problem becomes,

Minimize, Machining time (T)

Subject to, $0.4 \leq \mathrm{R}_{\mathrm{a}} \leq 0.6$

$\varphi=[0,30]^{\circ}, \mathrm{d}=\{6,7,8,9,10\} \mathrm{mm}, \mathrm{S}=\{316,520,715\} \mathrm{rpm}$,

$\mathrm{f}_{\mathrm{x}}=[0.2,0.4] \mathrm{mm}, \mathrm{f}_{\mathrm{y}}=[22,44] \mathrm{mm} / \mathrm{min}$, and $\mathrm{t}=[0.1,0.3] \mathrm{mm}$,

This is a mixed discrete-continuous constraint optimization problem. The global optimum solution for the above problem is computationally prohibitive to obtain. One of the reasons for the computational difficulty involves the undefined relationships of machining parameters with $\mathrm{T}$ and $\mathrm{R}$. Suitable data driven models for predicting $\mathrm{T}$ and $\mathrm{R}_{\mathrm{a}}$ are needed to be developed first. Then those models can be used to find at least some near-optimum solutions using available metaheuristic algorithms.

\section{Methodology}

In order to solve the optimization problem two new data driven ANFIS models are developed in our current study. For developing these ANFIS models, 74 experimental data are adopted from the experiments conducted by Hossain and Ahmad [4]. At first the most influential parameters are chosen based on exhaustive search method and some statistical analysis. Then best ANFIS models are selected based on leave-one-out Root Mean Square Error (RMSE). A leave-one-out (or $n$-fold) test is done by reserving one set of data for testing the model which is developed from rest of the data sets; this process is repeated for $n$ times for $n$ number of data sets Thus, the selected ANFIS models for predicting $\mathrm{T}$ and $\mathrm{R}_{\mathrm{a}}$ are used in the current research to solve the optimization problem stated in Eq. (1).

In this research, the stated optimization problem is solved with five different metaheuristic algorithms: Artificial Bee Colony (ABC) developed by Karaboga and Basturk [6], quick Artificial Bee Colony (qABC) proposed by Karaboga and Gorkemli [7], Ant Colony Optimization for real numbers (ACOr) developed by Socha and Dorigo [24], Modified Differential Evolution (MDE) developed by Angira and Babu [1], and a Simulated Annealing (SA) algorithm proposed by Bohachevsky, et al. [2]. A generalized discrete variables handling method that was proposed and implemented by Liao [13], is incorporated in all the algorithms in this research. Deb [3] parameter-less penalty methods are consistently used in all metaheuristics for handling the constraints. Each of the algorithms are run for 30 times allowing 100,000 number of function evaluations (only one stopping criteria) in each run. The best objective values (machining time, $\mathrm{T}$ ) and elapsed times are recorded from each run and each algorithm. The minimum function value among all of the runs and all of the five metaheuristics is found as 6.2106537581413 (minutes).

In the second step of the research, Hill-descent local search is incorporated in all of the five metaheuristics to make their hybrids. These hybrid metaheuristics are also run for 30 times. The stopping criteria are set with maximum number of function evaluation (maxnfe). Thus, the algorithm continues until the number of function evaluation (nfe) reaches to the maximum limit $(\operatorname{maxnfe}=100,000)$. The best function values (here it is machining time $\mathrm{T}$ ), and the elapsed time (et) are recorded for each of the 30 runs for each of the ten algorithms (five metaheuristics and their hybrids with local search). Analysis of variances (ANOVA) and pairwise comparison are performed to determine the significant differences between the results obtained from different metaheuristic algorithms (Li, et al. [10]). Based on the analysis $\mathrm{ABC}$ with local search $(\mathrm{ABC}+\mathrm{LS})$ is chosen as the most suitable metaheuristic algorithm for solving this problem.

In the third step of the research $\mathrm{ABC}+\mathrm{LS}$ algorithm is run for 5 times, allowing 1 million number of function of evaluation $(\operatorname{maxnfe}=1,000,000)$ in each run. This maxnfe is set as the only stopping criteria. The intention of this final run is to find more precise result, and to check if further improvement of the result can be possible. Matlab R2014b (Matlab 2014) is used for modifying all of the codes and the codes are run on a desktop computer with Intel@ Core $^{\mathrm{TM}} 2$ Duo $3.33 \mathrm{GHz}$ processor, 4GB RAM and 64-bit windows-7 enterprise operating system.

\section{Input Parameter (Variable) Selection}

Two separate stages of variable selection are performed before developing ANFIS models for average surface roughness $\left(R_{a}\right)$ and machining time (T). Exhaustive search method and statistical analysis with students' t-test have been used for both of the two cases. The parameter selection and ANFIS model development processes are described in the following subsections.

\section{ANFIS Model for Machining Time}

EXHSRCH function in Matlab has been used for exhaustively searching the combination of parameters, which are interactively influencing the machining time in a significant amount. In the search feed rate and radial depth of cut jointly provide the minimum training and testing errors (leave-one-out RMSE), which are 0.3147 and 0.6069 respectively, (refer to Figure $2 \mathrm{~b}$ ) compared to other combinations of parameters shown as in Figures 2(a) and 2(c).

Statistical analysis with Student's t-test also shows that feed rate $\left(f_{\mathrm{y}}\right)$ and radial depth $\left(\mathrm{f}_{\mathrm{x}}\right)$ are significant factors for machining time (T) (refer to Table 2). As a result feed rate and radial depth are selected as the most influential input parameters for $\mathrm{T}$ prediction.

Now, setting feed rate $\left(f_{y}\right)$ and radial depth $\left(f_{x}\right)$ as input parameters, several ANFIS models are developed with different architectures. The corresponding leave-one-out RMSE in machining time $(\mathrm{T})$ predictions are summarized in Table 3. From this table it can be noticed that smallest size ANFIS architecture 


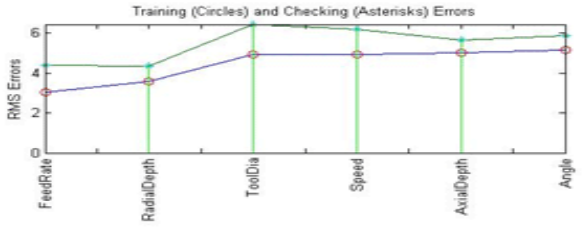

(a)

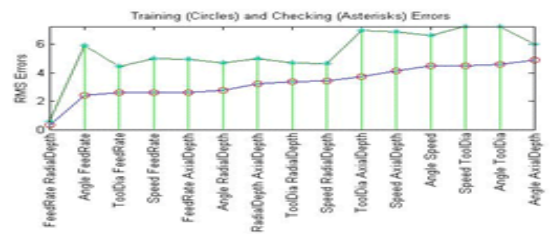

(b)

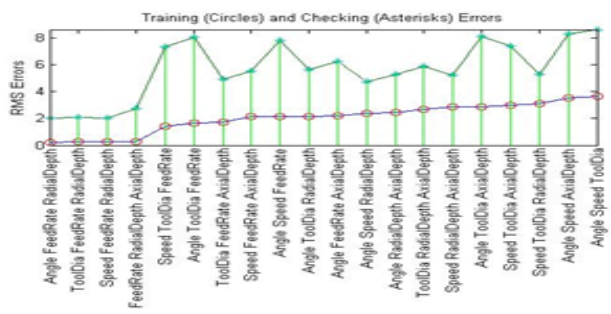

(c)

Figure 2:Exhaustive search results of parameter selection for Machining time prediction with, (a) Single parameter (b) Two parameters (c) Three parameters

Table 2: Summary of the statistical analysis for the parameters influencing for machining time, $\mathrm{T}$.

\begin{tabular}{|c|c|c|c|c|}
\hline Variable & $\begin{array}{c}\text { Parameter } \\
\text { Estimate }\end{array}$ & $\begin{array}{c}\text { Standard } \\
\text { Error }\end{array}$ & $\boldsymbol{t}$ value & 0.06 \\
\hline Angle & 0.00109 & 0.01975 & -1.41 & 0.9563 \\
\hline Speed & -0.00211 & 0.00150 & -0.21 & 0.8322 \\
\hline Tool Diameter & -0.03113 & 0.14631 & -16.23 & $<.0001$ \\
\hline Feed Rate & -0.42916 & 0.02645 & -15.84 & $<.0001$ \\
\hline Radial Depth & -45.50742 & 2.87257 & 0.41 & 0.6836 \\
\hline Axial Depth & 1.30584 & 3.18993 & & \\
\hline
\end{tabular}

Table 3: Different ANFIS Architectures for prediction of $T$ and corresponding leave-one-out RMSE.

Number of membership

functions for two input parameters

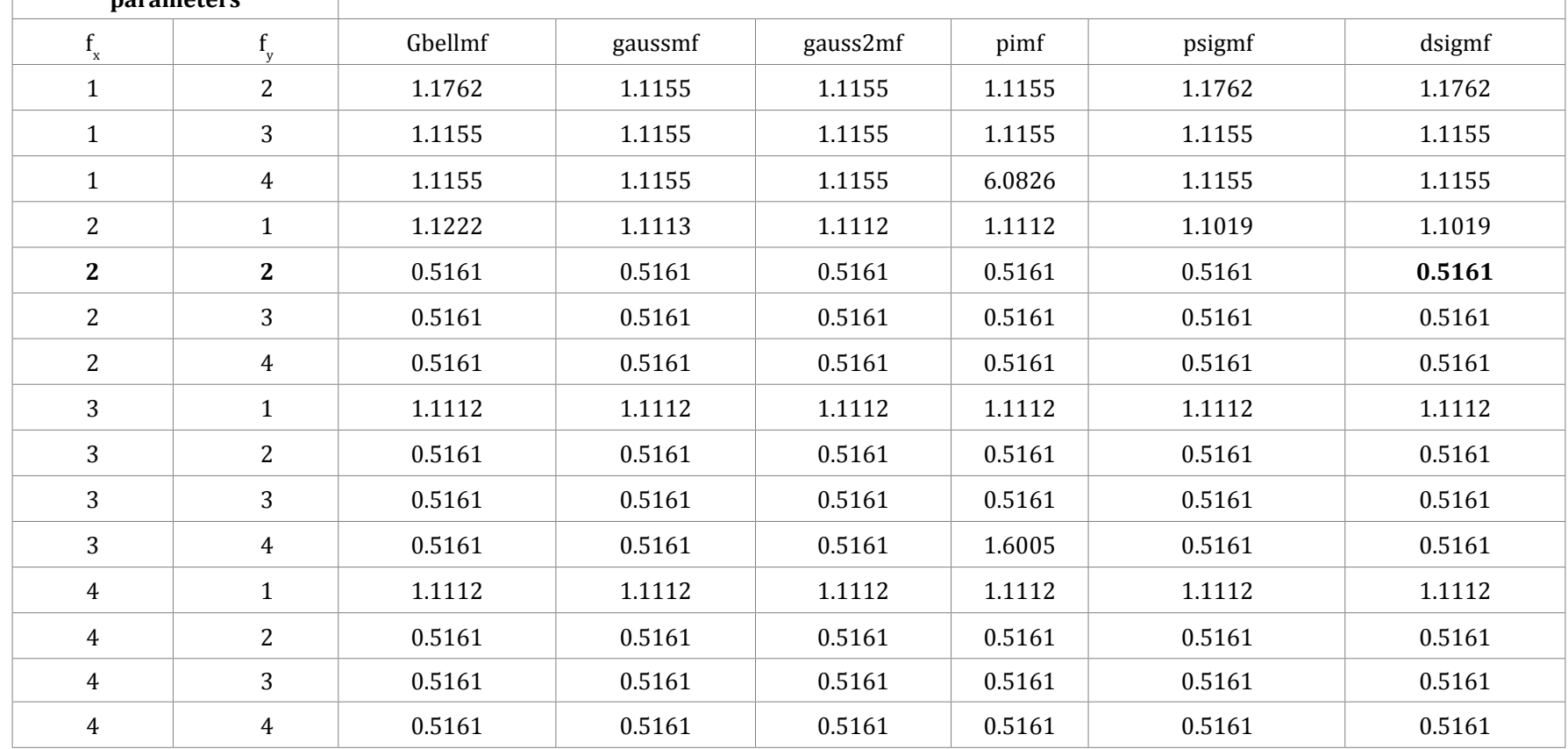


with $(2,2)$ number of membership functions has minimum leaveone-out RMSE $=0.5161$.

For simplicity the ANFIS model with dsigmf type of membership function has been chosen for machining time prediction. So, as shown in Figure 3, an ANFIS model with (2, 2) number of dsigmf type membership functions is used for machining time prediction for the optimization problem.

\section{ANFIS Model for Surface Roughness}

Exhaustive search with Matlab EXHSRCH function shows that a combination of input parameters-cutter axis inclination angle $(\varphi)$, tool diameter (d) and radial depth of cut $\left(f_{\mathrm{x}}\right)$ provides minimum training error $(\mathrm{RSME}=0.1077)$ and second minimum checking error (RMSE $=0.2702$ ) while predicting surface roughness, $\mathrm{R}_{\mathrm{a}}$ [refer to Figure $4(\mathrm{c})$ ].

At the same time, in Table 4, a statistical analysis with

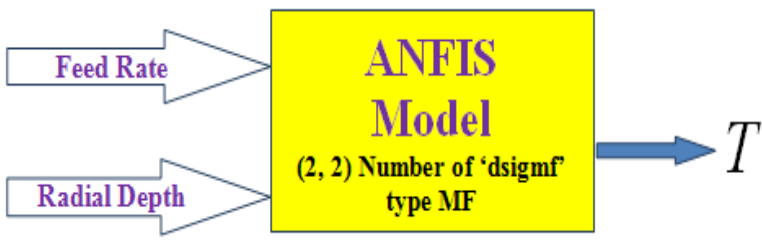

Figure 3:Selected ANFIS model for T prediction

students t-test shows that speed, feed rate and axial depth of cut are non-significant (with higher p-value). So it is wise to select cutter axis inclination angle $(\varphi)$, tool diameter (d) and radial depth of cut $\left(f_{x}\right)$ as the most influential input parameters for $R_{a}$ prediction.
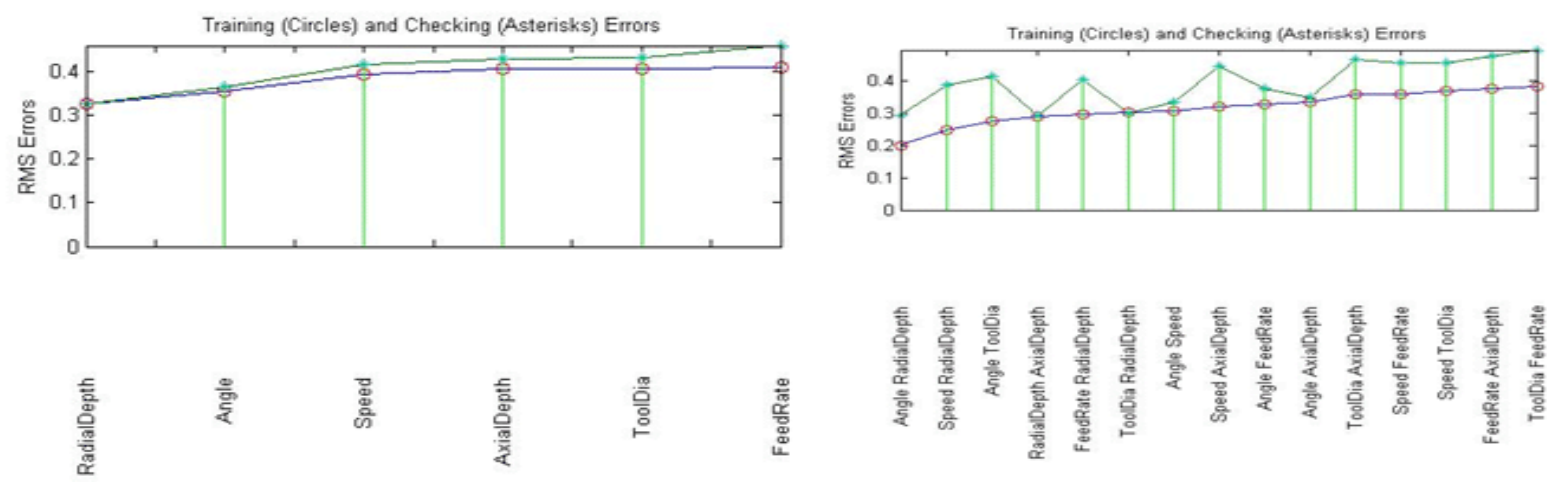

(a)

(b)
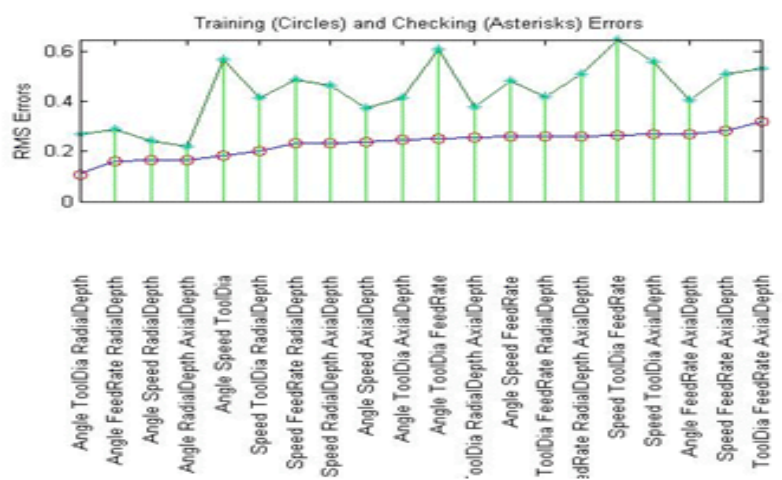

(c)

Figure 4:Exhaustive search results of parameter selection for $\mathrm{R}_{\mathrm{a}}$ prediction with, (a) Single parameter (b) Two parameters (c) Three parameters 
Table 4: Summary of the statistical analysis for the parameters influencing surface roughness, $R_{a^{*}}$

\begin{tabular}{|c|c|c|c|c|}
\hline Variable & Parameter Estimate & Standard Error & t-value & Pr $>|\mathbf{t}|$ \\
\hline Angle & 0.01823 & 0.00276 & 6.61 & $<.0001$ \\
\hline Speed & 0.00012180 & 0.00020932 & 0.58 & 0.5626 \\
\hline Tool Diameter & -0.05289 & 0.02043 & -2.59 & $\mathbf{0 . 0 1 1 8}$ \\
\hline Feed Rate & 0.00340 & 0.00369 & 0.92 & 0.3608 \\
\hline Radial Depth & 3.61971 & 0.40117 & 9.02 & $<.0001$ \\
\hline Axial Depth & -0.01237 & 0.44549 & -0.03 & 0.9779 \\
\hline
\end{tabular}

In Table 5 different ANFIS models for $\mathrm{R}_{\mathrm{a}}$ prediction, are summarized. This table shows that $(2,3,3)$ number of membership functions for three input parameters, angle, tool diameter and radial depth, respectively, and dsigmf type of membership function provide the minimum leave-one-out RMSE value 0.2207. So this ANFIS architecture as shown in Figure 5, is selected as the model for prediction of $\mathrm{R}_{\mathrm{a}}$.

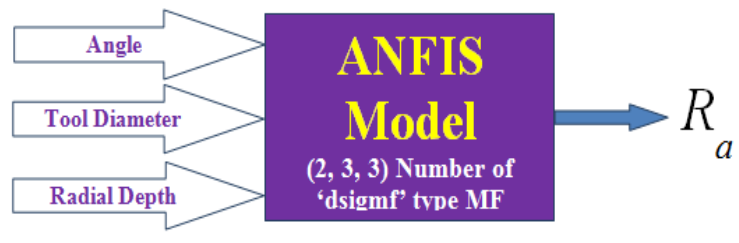

Figure 5:Selected ANFIS model for $\mathrm{R}_{\mathrm{a}}$ prediction

\begin{tabular}{|c|c|c|c|c|c|c|c|c|}
\hline \multicolumn{3}{|c|}{$\begin{array}{l}\text { Number of membership function for } \\
\text { three input parameters }\end{array}$} & \multicolumn{6}{|c|}{ Type of Input Membership Functions and corresponding leave-one-out RMSE } \\
\hline$\varphi$ & $d$ & $f_{x}$ & Gbellmf & gaussmf & gauss $2 \mathrm{mf}$ & pimf & psigmf & dsigmf \\
\hline 2 & 2 & 3 & 0.2378 & 0.2655 & 0.3565 & 0.3155 & 0.2380 & 0.2380 \\
\hline 2 & 2 & 4 & 0.2578 & 0.2654 & 0.3566 & 0.3155 & 0.2379 & 0.2387 \\
\hline 2 & 3 & 2 & 0.3178 & 0.4777 & 0.3051 & 0.3021 & 0.4639 & 0.4639 \\
\hline 2 & 3 & 3 & 0.2222 & 0.2221 & 0.2220 & 0.2258 & 0.2216 & 0.2207 \\
\hline 2 & 3 & 4 & 0.2210 & 0.2212 & 0.2257 & 0.2253 & 0.2259 & 0.2259 \\
\hline 2 & 4 & 2 & 0.3502 & 0.2537 & 0.3052 & 0.3021 & 0.4638 & 0.4638 \\
\hline 2 & 4 & 3 & 0.2225 & 0.2221 & 0.2227 & 0.2259 & 0.2260 & 0.2259 \\
\hline 2 & 4 & 4 & 0.2218 & 0.2208 & 0.2255 & 0.2260 & 0.2260 & 0.2260 \\
\hline 3 & 2 & 2 & 0.2927 & 0.3600 & 0.2797 & 0.2778 & 0.2810 & 0.2811 \\
\hline 3 & 2 & 4 & 0.4060 & 0.2469 & 0.3383 & 0.4133 & 0.3724 & 0.3740 \\
\hline 3 & 3 & 2 & 0.2273 & 0.2269 & 0.2388 & 0.2452 & 0.2428 & 0.2427 \\
\hline 3 & 3 & 3 & 0.2398 & 0.2419 & 0.2777 & 0.2793 & 0.2769 & 0.2769 \\
\hline 3 & 3 & 4 & 0.2353 & 0.2459 & 0.2777 & 0.2793 & 0.2779 & 0.2779 \\
\hline 3 & 4 & 2 & 0.2278 & 0.2260 & 0.2326 & 0.2377 & 0.2334 & 0.2333 \\
\hline 3 & 4 & 3 & 0.2420 & 0.2372 & 0.2779 & 0.2793 & 0.2655 & 0.2325 \\
\hline 3 & 4 & 4 & 0.2490 & 0.2398 & 0.2779 & 0.2793 & 0.2772 & 0.2774 \\
\hline 4 & 2 & 2 & 0.2791 & 0.2654 & 0.2735 & 0.2726 & 0.2746 & 0.2746 \\
\hline 4 & 2 & 3 & 0.3135 & 0.3064 & 0.2817 & 0.2770 & 0.3310 & 0.3235 \\
\hline 4 & 2 & 4 & 0.3147 & 0.2936 & 0.2788 & 0.2796 & 0.3527 & 0.3469 \\
\hline 4 & 3 & 2 & 0.2305 & 0.2311 & 0.2363 & 0.2368 & 0.2371 & 0.2362 \\
\hline 4 & 3 & 3 & 0.2432 & 0.2359 & 0.2648 & 0.2788 & 0.2483 & 0.2493 \\
\hline 4 & 4 & 2 & 0.2295 & 0.2298 & 0.2323 & 0.2326 & 0.2330 & 0.2321 \\
\hline 4 & 4 & 3 & 0.2394 & 0.2293 & 0.2700 & 0.2794 & 0.2490 & 0.2355 \\
\hline 4 & 4 & 4 & 0.2481 & 0.2271 & 0.2792 & 0.2794 & 0.2790 & 0.2790 \\
\hline
\end{tabular}




\section{Optimization}

The prime objective of this research is to find the optimum values of selected machining parameters in order to minimize machining time for a desired surface roughness. The input parameters have some boundary constraints. One of them (tool diameter d) has some discrete values and other variables are continuous within some minimum and maximum boundaries. In order to handle this non-linear mixed discrete-continuous optimization problem, five popular metaheuristics are used. The applied metaheuristics are, (i) Artificial Bee Colony (ABC), (ii) Quick Artificial Bee Colony (qABC), (iii) Ant Colony Optimization for real numbers (ACOr), (iv) Modified Differential Evolution (MDE) and (v) Simulated Annealing (SA). In addition to these single metaheuristics, five hybrid algorithms are also applied. These hybrid algorithms are developed by incorporating hill descent Local Search (LS) in the original metaheuristics listed above. The local search strategy, constraint handling heuristics, discrete variable handling and search parameters for different metaheuristics are discussed below.

\section{Local Search Strategy}

The Hill Descent (HD) local search is incorporated in the five metaheuristics (ABC, qABC, ACOr, MDE and $\mathrm{SA}$ ) to make them hybrid. The local search is applied on each global best solution when it is improved. Once an improved global best solution is traced in any iteration, HD is applied at most 5D times, where $\mathrm{D}=4$ is the dimension of the problem. So, maximum number of function evaluation in a local search would be 20 .

\section{Constraint Handling}

This is a constraint optimization problem. However, the original metaheuristics that are going to be used, are not inher- ently capable of handling constraints. So, the parameter-less penalty method proposed by Deb [3] is used in every metaheuristics while doing any sorting or comparison between two or more candidate solutions. Deb's method has three heuristic rules, these are, (1) feasible solution is preferred to infeasible solution, (2) among feasible solutions, lower function value is preferred and (3) among infeasible solutions, smaller constraint violation is preferred.

\section{Discrete Machining Parameter Handling}

In the optimization problem, the tool diameter $d$, is a discrete parameter. Other parameters are continuous. The original metaheuristics (ABC, qABC, ACOr, MDE and SA) are developed for handling only continuous variables. So for discrete variable (machining parameters, in our case) handling the same strategy as used by Liao [13], is used in this research as well. A randomly generated solution point for tool diameter is rounded to its nearest integer and that integer value indicates the position of candidate solution point in the dimension of tool diameter.

\section{Search Parameters for Metaheuristics}

The search parameters for different metaheuristics act important roles for the performance of that metaheuristic. So, the selection of search parameters is an important issue while selecting an appropriate optimization algorithm. The search parameters listed in Table 6 are chosen for the five metaheuristics based on some preliminary study results. Note that, D is the dimension of the problem, which are 4 here.

Another point has to be noted that, $\mathrm{ABC}$ and $\mathrm{qABC}$ are modified for handing constraint optimization problem following the approach by Karaboga and Akay (2011), to compute the probability of selecting a food source by the onlooker bees.

\begin{tabular}{|c|c|c|}
\hline Metaheuristics & & Parameters \\
\hline ABC: & $\begin{array}{l}1 \\
2 \\
3 \\
4\end{array}$ & $\begin{array}{l}\text { Maximum number of cycles, } \text { maxCycle }=2000 ; \\
\text { The number of colony size (employed bees }+ \text { onlooker bees), } N P=50 \\
\text { The number of food sources, FoodNumber }=N P / 2 ; \\
\text { A food source which could not be improved through, limit }=D^{*} \text { FoodNumber, trials is } \\
\text { abandoned by its employed bee }\end{array}$ \\
\hline \multirow{2}{*}{$\begin{array}{l}\text { qABC: } \\
\text { ACOr: }\end{array}$} & \multicolumn{2}{|c|}{ Additional parameter for quick $\mathrm{ABC}, r v=1$} \\
\hline & $\begin{array}{l}1 \\
2 \\
3 \\
4\end{array}$ & $\begin{array}{l}\text { The number of ants, ants }=50 \\
\text { Size of the archive, sar }=D^{*} 10 \\
\text { Parameter that controls intensification vs. diversification, } q=0.7 \\
\text { Scaling parameter }(\xi) \text {, that controls the convergence speed, } x i=0.7\end{array}$ \\
\hline MDE: & $\begin{array}{l}1 \\
2 \\
3\end{array}$ & $\begin{array}{l}\text { Population size, } n p=10^{*} D \\
\text { Amplification factor, } f 0=0.5 \\
\text { Crossover threshold, } c r=0.1\end{array}$ \\
\hline SA: & $\begin{array}{l}1 \\
2 \\
3 \\
4 \\
5\end{array}$ & $\begin{array}{l}\text { Maximum number of iterations at each temperature, } \text { maxitr }=500 \\
\text { Max temperature, } \operatorname{Tmax}=100 \\
\text { Cooling rate, alpha }=0.95 \\
\text { Maximum initial step size, } d r=0.3^{*} D R,(D R \text { is the domain range }) \\
g 0=0 \text {, for the standard simulated annealing }\end{array}$ \\
\hline
\end{tabular}




\section{Result and Discussion}

The ultimate objective of the research is to optimize the selected machining parameters for minimum machining time under surface roughness constraints. This optimization problem is non-linear and ANFIS model based. It is a constraint mixed discrete-continuous optimization problem. Based on the variable reduction done in ANFIS model for machining time section, the problem can be summarized as below,

Minimize Machining time ( $\mathrm{T}$ )

Subject to, $0.4 \leq \mathrm{R}_{\mathrm{a}} \leq 0.6$

Angle $=[0,30]$, Tool Dia $=\{6,7,8,9,10\}$, Radial Depth $=[0.2,0.4]$, Feed Rate $=[22,44]$,

where machining time $\mathrm{T}$ is dependent on radial depth of cut and feed rate; whereas $R_{a}$ depends on angle, tool diameter and radial depth of cut.

Results of the optimization using five metaheuristics and their hybrids are summarized in this section. The summa- ry statistics for the best objective value (machining time T) and the elapsed time for all of the ten algorithms are listed in Table 7. It is observed in Table 7 that $\mathrm{qABC}+\mathrm{LS}$ provides the minimum mean best objective value. On the other hand, $\mathrm{ABC}+\mathrm{LS}$ shows the minimum average elapsed time. Before final selection of a suitable algorithm for solving the stated optimization problem, some statistical analysis is needed to be done in order to identify the statistical significance of the metaheuristics and the Local Search (LS) strategy. The experiments are independent and the experimental data satisfy the tests for normality and homogeneity of variances. Hence the data set satisfies the necessary Assumptions For Analysis Of Variance (ANOVA) test.

In Table 8, a one-way ANOVA is prepared for testing the hypothesis that, "all ten algorithms provide the same mean best objective value". Very low p-value indicates that this hypothesis can be rejected and can be concluded that at least one of the algorithms provides significantly different result from the others.

\begin{tabular}{|c|c|c|c|c|c|c|c|c|c|c|}
\hline \multirow{2}{*}{ Table 7: Summary statistics from 30 runs } \\
\hline \multirow{2}{*}{ Algorithm } & \multicolumn{3}{|c|}{ Best objective value (machining time T) } & Min. & Mean & Median & SD & Max. & Min. \\
\cline { 2 - 13 } & Mean & Median & SD & Max. & Min. & Elapsed time \\
\hline ABC & 6.211840 & 6.210668 & 0.005607 & 6.241470 & 6.210654 & 124.2495 & 121.7891 & 5.7559 & 136.3281 & 118.4219 \\
\hline qABC & 6.210928 & 6.210656 & 0.000806 & 6.214078 & 6.210654 & 125.1839 & 124.8829 & 2.8585 & 137.5938 & 122.1406 \\
\hline ACOr & 6.507356 & 6.357017 & 0.867013 & 11.070938 & 6.210654 & 138.2151 & 136.0703 & 7.0851 & 160.6563 & 128.4844 \\
\hline MDE & 6.227914 & 6.211440 & 0.025091 & 6.268045 & 6.210654 & 171.5990 & 171.3203 & 2.3361 & 178.2500 & 167.6250 \\
\hline SA & 10.669694 & 11.119450 & 1.373818 & 11.173225 & 6.390841 & 187.3985 & 189.7188 & 12.2103 & 197.5469 & 124.3438 \\
\hline ABC+LS & 6.210659 & 6.210654 & 0.000010 & 6.210701 & 6.210654 & 123.5781 & 123.2032 & 2.0197 & 127.7500 & 120.1250 \\
\hline qABC+LS & $\mathbf{6 . 2 1 0 6 5 6}$ & 6.210654 & 0.000005 & 6.210678 & 6.210654 & 129.9229 & 129.3985 & 4.6715 & 148.1406 & 123.8438 \\
\hline ACOr+LS & 6.329462 & 6.268029 & 0.091311 & 6.446005 & 6.210654 & 148.4802 & 146.6797 & 7.9111 & 166.5781 & 140.0781 \\
\hline MDE+LS & 6.226021 & 6.210661 & 0.025765 & 6.268030 & 6.210654 & 174.5307 & 173.8829 & 4.2660 & 191.8750 & 170.1406 \\
\hline SA+LS & 9.143974 & 10.962028 & 2.457933 & 13.764865 & 6.265273 & 182.4386 & 189.6563 & 20.6365 & 196.6406 & 122.7031 \\
\hline
\end{tabular}

Table 8: One-way ANOVA, testing significance of algorithms in terms of best objective value

\begin{tabular}{|l|c|c|c|c|}
\hline Source & Sum Sq. & d.f. & Mean Sq. & Prob>F \\
\hline Algorithms & 673.213 & 9 & 74.8015 & 86.08 \\
\hline Error & 252.015 & 290 & 0.869 & \\
\hline Total & 925.229 & 299 & & \\
\hline
\end{tabular}

In order to test the significance of the metaheuristics, the local search strategy and their interaction on the best objective value, a two-way ANOVA is developed [shown in Table 9]. This two-way ANOVA test shows that there are significant effects of local search strategy $(\mathrm{p}$-value $=0.0017)$, metaheuristics $(\mathrm{p}$ value $=0)$ as well as their interactions $(p$-value $=0)$ on the best objective value.

On the other hand, in Table 10, a one-way ANOVA is prepared for testing the hypothesis that "all of the ten algorithms take same mean elapsed time". Very low p-value provides sufficient evidence to reject this hypothesis and it can be concluded that at least one of the algorithms takes significantly different elapsed time compared to others.

In order to test the significance of the metaheuristics, the local search strategy and their interaction on the elapsed time, a two-way ANOVA is also developed [shown in Table 11]. This two-way ANOVA test informs that there are significant effects of local search strategy ( $p$-value $=0.0163)$, metaheuristics $(\mathrm{p}$-value $=0)$ as well as their interactions $(\mathrm{p}$-value $=0.0001)$ on the elapsed time for computation. 


\begin{tabular}{|c|c|c|c|c|c|}
\hline Source & Sum Sq. & d.f. & Mean Sq. & $\mathbf{F}$ & Prob $>F$ \\
\hline Local Search & 8.741 & 1 & 8.741 & 10.06 & 0.0017 \\
\hline Metaheuristics & 637.821 & 4 & 159.455 & 183.49 & 0 \\
\hline Local Search*Metaheuristics & 26.651 & 4 & 6.663 & 7.67 & 0 \\
\hline Error & 252.015 & 290 & 0.869 & & \\
\hline Total & 925.229 & 299 & & & \\
\hline
\end{tabular}

Table 10: 1-way ANOVA, testing significance of algorithms in terms of elapsed time

\begin{tabular}{|l|c|c|c|c|c|}
\hline Source & Sum Sq. & d.f. & Mean Sq. & F & Prob>F \\
\hline Algorithms & 181121.1 & 9 & 20124.6 & 258.47 & $6.75886 \mathrm{e}-133$ \\
\hline Error & 22579.5 & 290 & 77.9 & & \\
\hline Total & 203700.5 & 299 & & & \\
\hline
\end{tabular}

Table 11: 2-way ANOVA for testing significance of local search and metaheuristics for elapsed time

\begin{tabular}{|l|c|c|c|c|c|}
\hline Source & Sum Sq. & d.f. & Mean Sq. & F & Prob>F \\
\hline Local Search & 454.2 & 1 & 454.2 & 5.83 & 0.0163 \\
\hline Metaheuristics & 178698.9 & 4 & 44674.7 & 573.78 & 0 \\
\hline Local Search*Metaheuristics & 1967.9 & 4 & 492 & 6.32 & 0.0001 \\
\hline Error & 22579.5 & 290 & 77.9 & & \\
\hline Total & 203700.5 & 299 & & & \\
\hline
\end{tabular}

From the above statistical analysis based on ANOVA, it is evident that all of the 10 algorithms do not provide the same results all the time, and their performances are not same in terms of best objective value and elapsed time. Thus to identify the best algorithm, a pairwise comparison is necessary. A complete pairwise comparison is done and graphically presented in Figure 6 and 7. In these figures, the confidence intervals of best objective value as well as elapsed time are constructed with $5 \%$ level of significance.

It is noticeable from Figure 6 and 7 that SA and SA+LS give significantly higher results in terms of best objective value, whereas ACOr, MDE and SA (with or without LS) show significantly higher results for mean elapsed time. From Table 7, we see that the mean of best objective values and the mean of elapsed times for both SA and SA+LS are worse than any other algorithms. So, we can reject SA and SA+LS depending on our observation. Though SA improves with local search [refer to Table 7], ACOr with local search takes more time for computations. Thus the impact of local search is evident.

On the other hand, in terms of mean elapsed time measurements, $\mathrm{ABC}, \mathrm{qABC}$ and their hybrids with local search give significantly faster (elapsed time) results compared to other algorithms. There is no significant difference observed during pairwise comparison between $\mathrm{ABC}, \mathrm{ABC}+\mathrm{LS}$, $\mathrm{qABC}$ and $\mathrm{qABC}+\mathrm{LS}$ [refer to Figures 6 and 7]. So we can chose an algorithm among these four. It has been noted earlier from Table 7 that $\mathrm{qABC}+\mathrm{LS}$ provides the minimum mean of the best objective values, and $\mathrm{ABC}+\mathrm{LS}$ provides the minimum average elapsed time. So it would be a good choice to compare between $\mathrm{qABC}+\mathrm{LS}$ and $\mathrm{ABC}+\mathrm{LS}$ for the final selection of optimization algorithm. Though there is no significant difference between these two algorithms with
$5 \%$ level of significance, the higher elapsed time is noticeable for $\mathrm{qABC}+\mathrm{LS}$ in Figure 7. So the best choice of algorithm for solving the stated optimization problem can be $\mathrm{ABC}+\mathrm{LS}$.

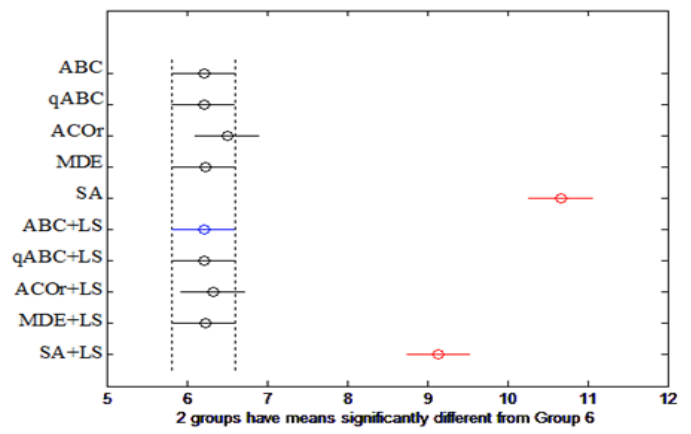

Figure 6:Comparison among ten algorithms in terms of best objective value.

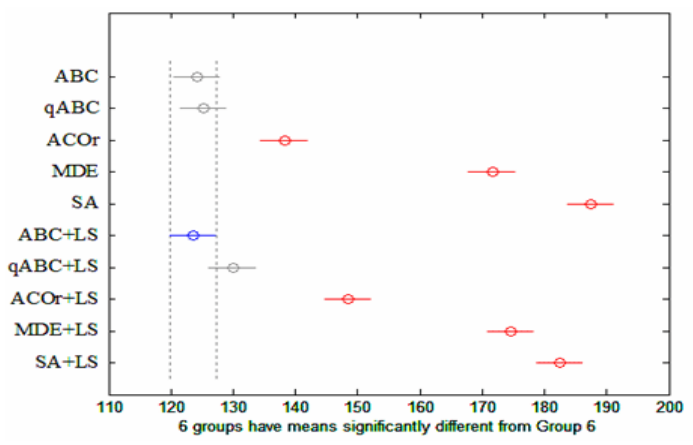

Figure 7:Comparison among ten algorithms in terms of elapsed time. 


\section{Final Run}

The $\mathrm{ABC}+\mathrm{LS}$ is finally chosen as the best algorithm for its rapid convergence and better results. This algorithm is used for the final runs for solving the stated optimization problem. This time for the final runs, the algorithm is run for 5 times allowing 1 million $(1,000,000)$ function evaluations, intending to check any further improvement or more precise result. This final runs provide better and precise result (Best objective value 6.210653758141266) than the previous runs (during algorithm selection), which was 6.2106537581413 . The outcomes from the 5 runs are listed in Table 12.

\begin{tabular}{|c|c|c|c|c|c|c|}
\hline \multirow[t]{2}{*}{ Run } & \multirow{2}{*}{$\begin{array}{c}\text { Best Objective Value } \\
\text { Machining time, } \\
T \text { (min) }\end{array}$} & \multicolumn{4}{|c|}{ Optimum Parameters } & \multirow{2}{*}{$\begin{array}{c}\text { Average Surface } \\
\text { Roughness, } \\
\boldsymbol{R}_{a}(\mu \mathrm{m})\end{array}$} \\
\hline & & $\begin{array}{c}\text { Angle, } \varphi \\
\text { (Degrees) }\end{array}$ & $\begin{array}{l}\text { Tool dia, } \\
d(\mathrm{~mm})\end{array}$ & $\begin{array}{l}\text { Radial Depth, } f_{x} \\
(\mathrm{~mm})\end{array}$ & $\begin{array}{l}\text { Feed Rate, } f_{y} \\
(\mathrm{~mm} / \mathrm{min})\end{array}$ & \\
\hline 1 & 6.210653758141266 & $\mathbf{0}$ & 6 & 0.340112541158715 & 38.872261879942734 & 0.600000000000000 \\
\hline 2 & 6.210653758141338 & 0 & 6 & 0.340112541158711 & 38.872261806581925 & 0.599999999999981 \\
\hline 3 & 6.210653758141528 & 0 & 6 & 0.340112541158702 & 38.872261805633649 & 0.599999999999931 \\
\hline 4 & 6.210653758981911 & 0.000000002561137 & 6 & 0.340112541119122 & 38.872261972040320 & 0.599999999994266 \\
\hline 5 & 6.210653758141266 & 0 & 6 & 0.340112541158715 & 38.872261905683651 & 0.600000000000000 \\
\hline
\end{tabular}

\section{Conclusion}

The research deals with a constraint mixed discretecontinuous optimization problem based on ANFIS models. The objective of the research is to find the minimum machining time for end milling operation on hot die steel (H13), under surface roughness constraints and to select the corresponding optimum machining parameter values. The problem is solved using five metaheuristics, $\mathrm{ABC}, \mathrm{qABC}, \mathrm{ACOr}, \mathrm{MDE}, \mathrm{SA}$ and their hybrids with hill descent local search. Based on the ability to find the best objective value (machining time) and the elapsed computational time, $\mathrm{ABC}$ with local search $(\mathrm{ABC}+\mathrm{LS})$ is chosen as a suitable metaheuristic algorithm for solving the stated problem. With the final run of ABC+LS metaheuristic algorithm, the best machining parameters are found as cutter axis inclination angle $=0$ degrees, tool diameter $=6 \mathrm{~mm}$, radial depth of cut $=$ $0.340112541158715 \mathrm{~mm}$ and feed rate $=38.872261879942734$ $\mathrm{mm} /$ minutes. These values of parameters give minimum machining time $\mathrm{T}_{\text {best }}=6.210653758141266$ minutes for average surface roughness of $R_{a} \approx 0.6 \mu \mathrm{m}$, which is very close to the maximum limit of desired surface roughness $R_{a}=0.6 \mu \mathrm{m}$.

These presented approaches are applicable in metal die manufacturing industries where end milling operation is done on hot die steel material using ball end mill cutters. The proposed approach can enhance the artificial intelligence level of the machine tools in order to facilitate the self-set-up capabilities for machining parameters and this will make the machine tools more versatile and intelligent. This research is indeed a little step towards the era of artificial intelligence.

\section{References}

1. Angira R, Babu BV. Optimization of process synthesis and design problems: a modified differential evolution approach. Chem Eng Sci. 2006;61(14):4707-4721.

2. Bohachevsky IO, Johnson ME, Stein ML. Generalized simulated annealing for function optimization. Technometrics. 1986;28(3):209-217.

3. Deb K. An efficient constraint handling method for genetic algorithms. Computer Methods in Applied Mechanics and Engineering. 2000;186(2-4):311-338.

4. Hossain MSJ, Ahmad N. Surface roughness prediction modeling for commercial dies using ANFIS ANN and RSM. IJISE. 2014;16(2):156183. DOI: 10.1504/IJISE.2014.058834

5. Kadirgama K, Noor MM, Alla ANA. Response ant colony optimization of end milling surface roughness. Sensors. 2010;10(3):2054-2063. DOI: $10.3390 / \mathrm{s} 100302054$

6. Karaboga D, Basturk B. A powerful and efficient algorithm for numerical function optimization: artificial bee colony $(\mathrm{ABC})$ algorithm. Journal of Global Optimization. 2007;39(3):459-471.

7. Karaboga D, Gorkemli B. A quick artificial bee colony (qABC) algorithm and its performance on optimization problems. Applied Soft Computing. 2014;23(1):227-238.

8. Karabulut $\mathrm{S}$, Karakoc H. Investigation of surface roughness in the milling of Al7075 and open-cell SiC foam composite and optimization of machining parameters. Neural Computing \& Applications. 2017;28(2):313-327.

9. Khanghah SP, Boozarpoor M, Lotfi M, Teimouri R. Optimization of micro-milling parameters regarding burr size minimization via RSM and simulated annealing algorithm. Transactions of the Indian Institute of Metals. 2015;68(5): 897-910.

10. Li Z, Kucukkocb I, Nilakantanc JM. Comprehensive review and evaluation of heuristics and meta-heuristics for two-sided assembly line balancing problem. Computers and Operations Research. 2017;84:146161.

11. Liao TW. Two hybrid differential evolution algorithms for engineering design optimization. Applied Soft Computing. 2009;10(4):1188-1199.

12. Liao TW. Feature extraction and selection from acoustic emission signals with an application in grinding wheel condition monitoring. Engineering Applications of Artificial Intelligence. 2010;23(1):74-84.

13. Liao TW, Kuo RJ, Hu JTL. Hybrid ant colony optimization algorithms for mixed discrete-continuous optimization problems. Applied Mathematics and Computation. 2012;219(6):3241-3252.

14. Madic M, Radovanovic M, Manic M, Trajanovic M. Optimization of ANN models using different optimization methods for improving CO2 laser cut quality characteristics. Journal of the Brazilian Society of Mechanical Sciences and Engineering. 2014;36(1):91-99.

15. Matlab. The MathWorks, Inc. 2014. Available from: http://www.mathworks.com/

16. Mellal MA, Williams EJ. Cuckoo optimization algorithm for unit pro- 
duction cost in multi-pass turning operations. International Journal of Advanced Manufacturing Technology. 2015;76(1-4):647-656.

17. Mukherjee R, Chakraborty S, Samanta S. Selection of wire electrical discharge machining process parameters using non-traditional optimization algorithms. Applied Soft Computing. 2012;12(8):2506-2516.

18. Pare V, Agnihotri G, Krishna C. Selection of optimum process parameters in high speed CNC end-milling of composite materials using metaheuristic techniques - a comparative study. Strojniski Vestnik-Journal of Mechanical Engineering. 2015;61(3):176-186.

19. Rao RV, Pawar PJ. Modelling and optimization of process parameters of wire electrical discharge machining. Journal of Engineering Manufacture. 2009;223(11):1431-1440.

20. Rao TB, Krishna AG. Selection of optimal process parameters in WEDM while machining Al7075/SiCp metal matrix composites. International Journal of Advanced Manufacturing Technology. 2014;73(1-4):299314.

21. Rong YM, Zhang GJ, Chang Y, Huang, Y. Integrated optimization model of laser brazing by extreme learning machine and genetic algorithm. International Journal of Advanced Manufacturing Technology. 2016;87(9-12):2943-2950.

22. Shukla R, Singh D. Experimentation investigation of abrasive water jet machining parameters using Taguchi and Evolutionary optimization techniques. Swarm and Evolutionary Computation. 2017;32:167-183.
23. Silva JA, Abellan-Nebot JV, Siller HR, Guedea-Elizalde F. Adaptive control optimisation system for minimising production cost in hard milling operations. International Journal of Computer Integrated Manufacturing. 2014; 27(4):348-360.

24. Socha K, Dorigo M. Ant colony optimization for continuous domains. European Journal of Operations Research. 2008;185(3):1155-1173.

25. Tamizharasan T, Bamabas JK. Optimization of cutting tool geometry based on flank wear - DoE, PSO and SAA approach. Indian Journal of Engineering and Materials Sciences. 2014;21(5):543-556.

26. Teimouri R, Baseri H. Optimization of magnetic field assisted EDM using the continuous ACO algorithm. Applied Soft Computing. 2014;14(C):381-389.

27. Yildiz AR. Optimization of cutting parameters in multi-pass turning using artificial bee colony-based approach. Information Sciences. 2013;220(1):399-407.

28. Yusup N, Sarkheyli A, Zain AM, Hashim SZM, Ithnin N. Estimation of optimal machining control parameters using artificial bee colony. Journal of Intelligent Manufacturing. 2014;25(6):1463-1472.

29.Zuperl U, Cus F. Machining process optimization by colony based cooperative search technique. Strojniski Vestnik-Journal of Mechanical Engineering. 2008;54(11):751-758. 